\title{
Benchmarking in a multiple criteria performance context: An application and a conceptual framework
}

\author{
Mário Augusto $^{\text {a,1 }}$, João Lisboa ${ }^{a, *}$, Mahmoud Yasin ${ }^{\text {b,2 }}$, José Rui Figueira ${ }^{c, 3}$ \\ a School of Economics, University of Coimbra, Institute of Systems and Robotics, Av. Dias da Silva, 165, 3004-512 Coimbra, Portugal \\ ${ }^{\mathrm{b}}$ Department of Management and Marketing, East Tennessee State University, P.O. Box 70625, Johnson City, TN 37614, United States

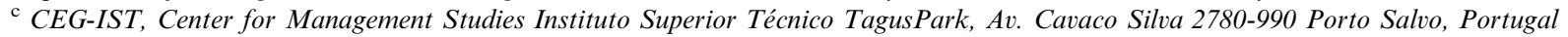

Received 10 May 2005; accepted 26 October 2006

Available online 26 December 2006

\begin{abstract}
This article presents a conceptual benchmarking framework which applies a multiple criteria approach to assess performance. In the process, a multiple criteria procedure is used to assess the performance of three hundred and ninety two (392) Portuguese firms. Based on the results of this procedure, a conceptual framework is devised to facilitate addressing relevant benchmarking implications. The framework is designed to provide a conceptual linkage between the performance measurement methodology and the organizational benchmarking system.
\end{abstract}

(C) 2006 Elsevier B.V. All rights reserved.

Keywords: Benchmarking; Multiple criteria approach; Portuguese firms

\section{Introduction}

The Portuguese economy, not unlike its counterparts across the globe, has to deal with the new realities, challenges and opportunities brought about by the globalization of most business activities. In this context, firms, industries and entire sectors operating within the Portuguese economy have experienced varying degrees of success in coping with

\footnotetext{
* Corresponding author. Tel.: +351 239 790596; fax: +351 239 403511.

E-mail addresses: maugusto@fe.uc.pt (M. Augusto), lisboa@ fe.uc.pt (J. Lisboa), mmyasin@etsu.edu (M. Yasin), figueira@ist. utl.pt (J.R. Figueira).

${ }^{1}$ Tel.: +351 239 790544; fax: +351239403511.

${ }^{2}$ Tel.: +1 423439 5877; fax: +1 4234395661 .

${ }^{3}$ Tel.: +351 21423 3507; fax: +35121423 3568 .
}

the global winds of competitive change. Therefore, investors and managers (decision-makers) alike are having to assess economic performance in a relatively new context. This is especially true, in light of the integration of the Portuguese economy into the European marketplace.

In highly competitive marketplace, such as in the case of the European market, the road to effective performance is not without challenges and obstacles. To meet these challenges and overcome these obstacles, an organization must have a clear understanding of its performance in relation to its competitors. Once such a vision is achieved, the organization must engage in a systematic benchmarking process aiming at enhancing performance in the context of continuous improvement. To accomplish this task, an organization must have 
an organizational benchmarking system which is occupied with analytical models designed to measure multifaceted performance characteristics and parameters. In short, the benchmarking system must include a systematic and practical performance measurement methodology. Such a methodology should be designed to facilitate the competitive analysis of different aspects of organizational performance.

The relative performance of organizations and sectors within a given economy can be assessed using different types of traditional methodologies. In this context, however it is important to select a methodology, which is systematic, practical and proven. Such an evaluation methodology should be multiple criteria in nature due to the multifaceted nature of economic and/or business performance. Also, the selected evaluation methodology should be conducive to the decision-making/"problemsolving" process. Thus, it should lend itself to practical implications and implementable action plans, both concerning comparative performance analysis and benchmarking.

This study offers such a methodology. The process of ranking using a multiple criteria based methodology, has some implications to policy makers, investors and researchers. Based on the results of this multiple criteria application, a set of economical and financial indicators are proposed as benchmarks for Portuguese firms in their pursuit of high performance. A conceptual framework which incorporates the multiple criteria approach used in this study and benchmarking implications is advanced.

\section{Background}

Multiple criteria based methodologies have been effectively applied in engineering and natural sciences for many years. In this context, the theoretical rigors, and "robustness" of such methodologies, as well as their advantages over traditional methodologies, are well documented (Figueira et al., 2005). In recent years, some applications of multiple criteria based methodologies with decision-making and "problem-solving" implications found their ways to private and public sectors' business settings (see Figueira et al., 2005, Chapters 21, 22 and 23). However, these applications are to a large extent, still scarce in terms of numbers and scope. This is rather interesting, given the general adaptability of multi- ple criteria based methodologies to social sciences and business.

There have been numerous attempts at developing schemes to rank and group firms based on different performance measures. Among these attempts is the work of Thurston (2001), which examined the ranking of the World's 50 largest banks using total assets data. On the other hand, Wolin (2001) examined the ranking provided by Far Eastern Economic Review, a publication that has been ranking firms for many years. The respondents consisting of executives and professionals were asked to evaluate firms using a multiple criteria approach. The items evaluated included service and product quality, long-term management vision, innovative response to customer needs, financial soundness, and whether other firms try to emulate the firm. A weighted average statistical methodology was used to derive the firms' ranking.

Kerr (1999) analysed the ranking of oil firms, where a strong competitive climate existed. Firms were ranked based on oil reserves, natural gas reserves and production, as well as refinery capacity and sales. Ammar et al. (2000) used a multi-level fuzzy-rule based system to evaluate the relative ranking of state governments' performance. This approach used both financial criteria and experts' judgement.

This study utilises a multiple criteria approach to rank the performance of the Portuguese firms and suggests a set of economical and financial indicators to be used as a benchmarking.

As far as we know outranking based methods along indirect elicitation techniques to get the criteria weights are not frequently used when dealing with the ranking problem statement for companies. The techniques frequently used in magazines are quite elementary and mainly based on weighted averages, producing thus counterproductive or meaningfulness results. This was the main aspect that led us to build a different methodology for ranking firms.

The proposed multiple criteria approach used in this study is simple. Furthermore, it has the capacity to deal well with uncertainty, vagueness and/or inaccuracy. In this context, the proposed methodology can be used to provide robust conclusions. In our particular context, conclusion is said to be robust with respect to a domain of possible values for the weights, if there is no particular set of weight, which clearly invalidates the conclusion. This is why we define several sets of criteria weights 
and run ELECTRE algorithm. Insights gained from this applied research have practical implications to policy makers and investors. This study also contributes to an important, yet relatively new body of application-based literature dealing with a multiple criteria approach to decision-making.

The remainder of this study is organized as follows. After the background which represents an overview of the relevant literature, we introduce the current study and the methodology used. Then, data and sample used in this study are described. Next, the theoretical background of the multiple criteria methodology used in this study is presented. In the results we present the ranking obtained for the Portuguese companies and it is suggested a set of economical and financial indicators to be used by managers for benchmarking their firms. Finally, we present a conceptual benchmarking framework which incorporates the methodology and findings of the study.

\section{The study}

The multiple criteria approach utilized in this study draws on the logic of outranking based methods, in particular the ELECTRE III procedure for ranking problem statement (Roy and Bouyssou, 1993), aided by the SFR (Simos, Figueira and Roy procedure) Software to set the criteria weights (Figueira and Roy, 2002). The decision-maker need not be familiar with the procedural details of the methodology used.

\section{Sample}

The data used in this study was obtained from a database supplied by the magazine EXAME, in collaboration with the Dun \& Bradstreet and Arthur Andersen. This database contains data related to the highest performing and larger 500 Portuguese firms, excluding banks and insurance firms. To be included in the database, the firms have to respond to an inquiry submitted by Dun \& Bradstreet, and provide its balance and income statements. In order to have in the sample only firms with regular performance behaviour from the initial sample, 108 were eliminated. These firms are deleted for two main reasons. First, were excluded all the firms with incomplete information necessary to calculate all the performance indicators. Second, it was also decided to exclude from the sample all the firms,
Table 1

Data by economic sectors

\begin{tabular}{lr}
\hline Economic sector & Number of firms \\
\hline Agriculture and fishing & 1 \\
Agro-industry & 29 \\
Automobile sales industry & 34 \\
Basic metals & 18 \\
Cellulose and paper & 4 \\
Chemicals and chemical products & 17 \\
Clothes and leather & 6 \\
Construction industry & 44 \\
Distribution of combustible & 14 \\
Distribution of food products & 29 \\
Electrical and electronic material industry & 15 \\
Electricity, gas and water supply & 5 \\
Electronic and electrical trade & 13 \\
Hotels and restaurants & 7 \\
Hygiene and cleaning & 2 \\
Non-metallic mineral products & 18 \\
Pharmaceutical products & 31 \\
Publishing industry & 10 \\
Services & 21 \\
Telecommunications & 4 \\
Textiles & 13 \\
Trade & 32 \\
Transport equipment industry & 7 \\
Transportation and distribution & 9 \\
Wood, cork, and furniture & 9 \\
Total & 392 \\
\hline
\end{tabular}

with indicator values above or below the "mean \pm 3 standard deviation". This was done in order to avoid abnormal situations and errors due to deficient data collection (outliers). Firms in the database were grouped into twenty-five (25) sectors based on their main economic activities. Table 1 presents a sample profile in terms of the economic sector and number of firms in each sector.

\section{Criteria}

The criteria used to rank the firms are mainly economical and financial in nature. These criteria are designed to capture the multifaceted nature of performance for the firms. These criteria included:

(i) growth (sales and profit growth);

(ii) return on sales, equity and total assets (profitability of sales, return on equity and profitability of total assets);

(iii) capacity to meet commitments in the shortterm, medium-term, and long-term (solvency and liquidity);

(iv) efficiency of material usage (assets turnover); 
(v) productivity of the human factor (productivity of workers).

Al the criteria are to be maximized.

\section{Methodology}

Both ELECTRE III and SRF have been used successfully in different applications (Roy and Bouyssou, 1993; Figueira and Roy, 2002). The ELECTRE III method and SRF Software were used to analyze the problem addressed in this study. This choice was made due to the following factors:

(i) There exist a set of discrete alternatives (options) and a set of economical and financial indicators which can be easily converted into a set of criteria. In addition, the problem type addressed in this study can be modeled as a ranking problem. Based on the literature, the ELECTRE family of methods is judged to be appropriate to deal with a problem type such as the one addressed in this study (see Roy and Bouyssou, 1993). This is especially true for the ELECTRE III method.

(ii) The decision-maker is called upon to "assign" indirectly numerical values to the weights associated with the different criteria (Figueira and Roy, 2002).

(iii) Since it is rather difficult for the decisionmaker to assign directly a precise value to each criterion weight parameter, the SRF Software elicits the preferences of the decision-maker concerning the weights indirectly, with the aid of a simple questionnaire. In addition, the SRF Software is capable of defining and using several sets of weights as well as exploiting the information quickly under different assumptions.

(iv) Very often there exists uncertainty, vagueness and/or inaccuracy in relation to the data available. The ELECTRE III method is designed to deal with such conditions.

The ELECTRE III method was particularly designed to deal with the following problem type. Given a discrete set of alternatives $A=\left\{a_{1}, a_{2}, \ldots\right.$, $\left.a_{m}\right\}$, and a consistent family of criteria $F=\left\{g_{1}\right.$, $\left.g_{2}, \ldots, g_{n}\right\}$, the ELECTRE III method defines a partition over $A$ in a set of ordered classes. Then, it provides a ranking of these classes. Thus, expressing the relative position of each class in the ranking.
This process is accomplished based on two phases as follows:

1. Build a outranking binary relation for the set $A$. For each pair of alternatives $(a, b)$, the method assigns a value representing the degree by which " $a$ outranks $b$ ". The notion that " $a$ outranks $b$ " means that " $a$ is at least as good as $b$ ". This relationship is denoted as $a S b$.

2. Provide a ranking of the alternatives.

The ELECTRE III method is based on a pseudocriterion model. A pseudo-criterion is a criterion function, $g_{j}$, along with two thresholds, an indifference threshold, $q_{j}$, and a preference threshold, $p_{j}$ (see Roy, 1996). These thresholds are designed to account for the uncertainty, vagueness and/or inaccuracy of the data.

Let $g_{j}$ be the criterion function $j$, and $a$ and $b$ the two different alternatives from the set $A$. In a classic criterion model (also designed true-criterion model), if the performance measurement for $a$ and $b$ are the same $\left(g_{j}(a)-g_{j}(b)=0\right)$, then these alternatives are considered indifferent regarding criterion $g_{j}\left(a I_{j} b\right)$. Let us now consider the case where the value of $a$ remains fixed and the value of $b, g_{j}(b)$ increases. If, for example, uncertainty exists regarding the values of $a$ and $b$, it is legitimate to consider a non-zero, but an insignificant difference between the values of these two alternatives, as indifference as the part of the decision-maker forward these two alternatives. In such a case, there exists an indifference zone for insignificant differences between the values of $a$ and $b, g_{j}(a)-g_{j}(b)$.

On the other hand, if the value of alternative $b$ is slightly too increase, then the decision-maker may experience true hesitation, as to whether he/she should consider alternative $b$ as, now, truly having higher value than alternative $a$. Or, should the difference between these two values still be considered small, reflecting an indifference. Thus, there exists a zone of hesitation. We call this zone the zone of weak preference (hesitation is between strict preference and indifference) between $a$ and $b$ regarding criterion $g_{j}, b Q_{j} a$. However, when the difference between the values of $a$ and $b$ becomes large enough, then there exists a strict preference reflecting the fact that alternative $b$ is preferred relative to alternative $a$ regarding the criterion $g_{j}, b P_{j} a$.

The ELECTRE III method recognizes the existence of a veto power for each criterion, in relation to the assertion that " $a$ outranks $b$ ". If the difference 
of performances between the two alternatives $a$ and $b$ is so high for a certain discordant criterion $g_{j}$, we cannot consider that " $a$ outranks $b$ ", even if $a$ is better than $b$ in all other remaining criterion. The veto threshold $\left(v_{j}\right)$ represents a limit beyond which the discordance cannot go and allow an outranking. These veto thresholds are established by the analyst along with the decision-maker based on his/has feeling and experience. In this study the authors acted as the decision-maker. Table 2 reports the indifference, preference, and veto thresholds of the criteria used in this study.

The decision-maker is frequently called upon to "assign" directly a value for each criterion weight parameter representing the relative importance of each criterion. However, for most decision-makers, the process of assigning directly a precise value to each criterion is rather a very difficult task. Therefore, such information is elicited in an indirect way by using the SRF Software.

The SRF Software (http://www.lamsade.dauphine.fr/logiciel.html) is based on the Simos' revised procedure (Figueira and Roy, 2002). The software is designed to elicit the preferences of the decisionmaker and give an "appropriate" value to the weight of each criterion. The main advantages of this software are:

Table 2

Indifference, preference, and veto thresholds

\begin{tabular}{lllll}
\hline \multirow{2}{*}{ Criterion $\left(g_{j}\right)$} & \multicolumn{2}{l}{ Thresholds } & \\
\cline { 3 - 5 } & & $\begin{array}{l}\text { Indifference } \\
\left(q_{j}\right)\end{array}$ & $\begin{array}{l}\text { Preference } \\
\left(p_{j}\right)\end{array}$ & $\begin{array}{l}\text { Veto } \\
\left(v_{j}\right)\end{array}$ \\
\hline$g_{1}$ & Sales growth (\%) & 0.5 & 1 & 5 \\
$g_{2}$ & Profit growth (\%) & 0.5 & 1 & 3 \\
$g_{3}$ & Profitability of sales (\%) & 0.5 & 1 & 3 \\
$g_{4}$ & Return on equity (\%) & 0.5 & 1 & 5 \\
$g_{5}$ & Profitability of total & 0.5 & 1 & 3 \\
& assets (\%) & & & \\
$g_{6}$ & Solvency & 0.01 & 0.1 & - \\
$g_{7}$ & Liquidity & 0.01 & 0.1 & - \\
$g_{8}$ & Assets turnover & 0.05 & 0.1 & - \\
$g_{9}$ & $\begin{array}{l}\text { Productivity of the work } \\
\text { (1.000 USD) }\end{array}$ & 2.5 & 5 & 20 \\
\hline
\end{tabular}

Notes: $g_{1}$ measured by $\left[\left(\operatorname{Sales}_{t}-\mathrm{Sales}_{t-3}\right) / \mathrm{Sales}_{t-3}\right] \times 100 ; g_{2}$ measured by [(Earnings after interest and tax $x_{t}-$ Earnings after interest and $\left.\operatorname{tax}_{t-3}\right)$ /Earnings after interest and $\left.\operatorname{tax}_{t-3}\right] \times 100$; $g_{3}$ measured by (Earnings before interest and tax/Sales) $\times 100$; $g_{4}$ measured by (Earnings after interest and tax/Equity) $\times 100 ; g_{5}$ measured by (Earnings before interest and tax/Total of assets) $\times 100 ; g_{6}$ measured by Equity/Total of debt; $g_{7}$ measured by Current assets/Current liabilities; $g_{8}$ measured by Sales/Total of assets and $g_{9}$ measured by (Gross value add $/ N^{0}$ of workers). (i) It determines indirectly the numerical values for the weights, instead of asking the decision-maker to directly assign a weight to each criterion parameter. Thus, avoiding the difficult process involved in assigning direct precise values by the decision-maker.

(ii) The data is elicited through the use of a simple questionnaire. Thus the decision-maker does not need to be familiar with multiple criteria analysis techniques.

(iii) The software is capable of performing sensitivity and robustness analysis. Thus, allowing for testing the impact of uncertainty, vagueness and/or inaccuracy on the results.

The preferential information is "collected" from the decision-maker based on the following procedure:

1. Give to the decision-maker a set of cards where the name of each criterion and some complementary information is written on a card. Provide the decision-maker also with a set of blank cards.

2. The decision-maker ranks the cards, in such a way that the card corresponding to the first criterion in the ranking is the least important while the last is the most important. If some cards (criteria) are viewed as having the same importance, then the decision-maker must consider them a set of ex aequo or a class of equivalent criteria.

3. If two successive subsets ex aequo criteria in the ranking process can be more or less considered close, then the decision-maker should put a blank card between the successive subsets of ex aequo. The higher the difference of weights between two subsets of ex aequo, the more blank cards the decision-maker must put between these two subsets.

4. Finally, the decision-maker provides the difference between the weights of the least important and the most important criterion in the ranking, i.e., how many times the most important criterion is more important than the least important one.

In this study, the decision-maker did not feel confident enough to provide well-defined preferences. Thus, three different possible rankings were provided to the decision-maker (see Table 3). As it is difficult for most decision-maker to define the exact nature of the difference in importance between the most important criterion and the least important one, the decision-maker provides several scenarios 
Table 3

Ranking criteria scenarios

\begin{tabular}{llrrr}
\hline \multirow{2}{*}{ Criterion $\left(g_{j}\right)$} & \multicolumn{3}{c}{ Ranking } \\
\cline { 3 - 5 } & & $H_{1}$ & $H_{2}$ & $H_{3}$ \\
\hline$g_{1}$ & Sales growth (\%) & 4 & 4 & 3 \\
$g_{2}$ & Profit growth (\%) & 5 & 6 & 3 \\
$g_{3}$ Profitability of sales (\%) & 2 & 3 & 2 \\
$g_{4}$ Return on equity (\%) & 5 & 3 & 2 \\
$g_{5}$ Profitability of total assets (\%) & 4 & 3 & 2 \\
$g_{6}$ & Solvency & 3 & 2 & 2 \\
$g_{7}$ & Liquidity & 1 & 1 & 1 \\
$g_{8}$ & Assets turnover & 4 & 2 & 3 \\
$g_{9}$ Productivity of the work & 6 & 5 & 2 \\
& How many times is the most important & 5,7 & 5,7 & 4,5 \\
& criterion more important than the last & & & \\
$\quad$ important one & & & \\
\hline
\end{tabular}

Within each scenario the higher the number the more important is the criterion.

(values) for the number of times that the most important criterion is more important than the last important one. In our study, two scenarios (values) were used, as can it be seen in the last line of Table 3. Also, because it was difficult for the decisionmaker to determine the number of blank cards between two consecutive sets of ex aequo criteria, the decision-maker was given two scenarios for each ranking in terms of the number of blank cards, as shown in Table 4.

The elicitation process obtains the criteria weights by posing indirect questions to the decision-makers rather than asking them directly for the values of the criteria weights. The methodology used does not produce an average for each firm. Thus, it is not a weighted-sum-based method. There are several flaws related to the weighted-sum methods. The following two questions highlight some of these flaws. What happens when the unit for measuring objects changes? What kind of effects can we expect when the range of the criteria scales

Table 4

Options for the number of blank cards used

Equivalent sets of Number of blank cards between the criterion consecutive sets of criterion

\begin{tabular}{lcccccc} 
& $H_{1.1}$ & $H_{1.2}$ & $H_{2.1}$ & $H_{2.2}$ & $H_{3.1}$ & $H_{3.2}$ \\
\hline $5-6$ & 4 & 3 & 2 & 3 & - & - \\
$4-5$ & 2 & 1 & 2 & 1 & - & - \\
$3-4$ & 3 & 2 & 3 & 3 & - & - \\
$2-3$ & 1 & 1 & 3 & 2 & 3 & 2 \\
$1-2$ & 2 & 1 & 4 & 3 & 1 & 2 \\
Total of blank cards & 12 & 8 & 14 & 12 & 4 & 4
\end{tabular}

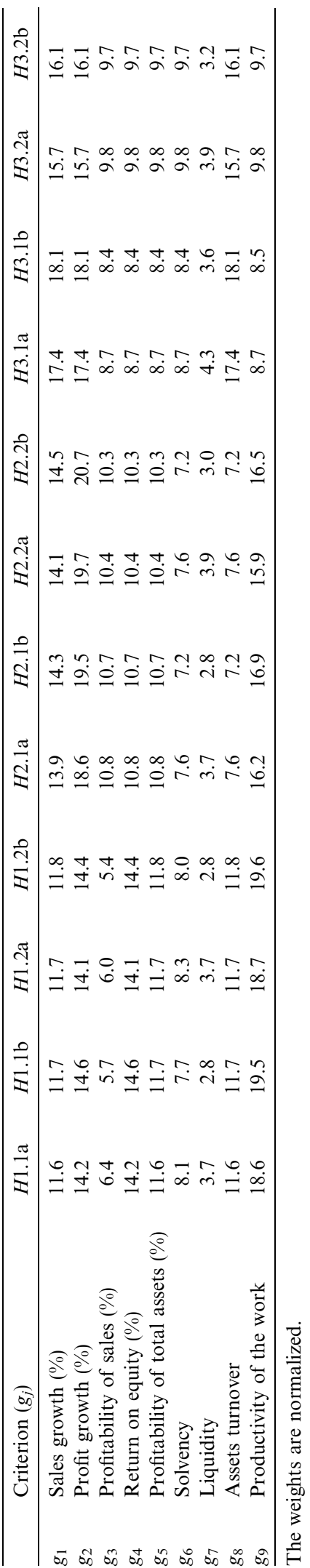


Table 6

Subsets of firms based on the performance criteria

\begin{tabular}{|c|c|c|c|c|c|c|c|c|}
\hline \# of firms & Economic sector & Subset & $\begin{array}{l}\text { \# of } \\
\text { firms }\end{array}$ & Economic sector & Subset & $\begin{array}{l}\text { \# of } \\
\text { firms }\end{array}$ & Economic sector & Subset \\
\hline 1 & Trade & 1 & 2 & Trade & $5-6$ & 2 & Automobile sales industry & $7-8$ \\
\hline 1 & Pharmaceutical products & & 1 & Automobile sales industry & & 1 & Chemicals and chemical products & \\
\hline 1 & Pharmaceutical products & $1-2$ & 1 & Transport equipment industry & & 2 & Trade & \\
\hline 1 & Distribution of food products & 2 & 1 & Construction industry & & 2 & Hotels and restaurants & \\
\hline 1 & Services & & 1 & Agro-industry & & 2 & Non-metallic mineral products & \\
\hline 1 & Services & $2-3$ & 1 & Cellulose and paper & & 3 & Services & \\
\hline 1 & Pharmaceutical products & & 2 & Transportation and distribution & 6 & 1 & Electronic and electrical trade & \\
\hline 1 & Pharmaceutical products & 3 & 1 & Construction industry & & 2 & Agro-industry & \\
\hline 1 & Clothes and leather & & 3 & Trade & & 2 & Electricity, gas and water supply & \\
\hline 3 & Pharmaceutical products & $3-4$ & 2 & Non-metallic mineral products & & 1 & Transportation and distribution & \\
\hline 1 & Distribution of combustible & & 1 & Basic metals & & 1 & Publishing industry & \\
\hline 1 & Services & & 2 & Pharmaceutical products & & 1 & Distribution of food products & \\
\hline 2 & Pharmaceutical products & 4 & 1 & Electricity, gas and water supply & & 1 & Trade & 8 \\
\hline 1 & Transport equipment industry & & 1 & Agro-industry & & 3 & Construction industry & \\
\hline 1 & Telecommunications & & 1 & Automobile sales industry & & 10 & Distribution of food products & \\
\hline 1 & Trade & & 1 & Electronic and electrical trade & $6-7$ & 2 & Automobile sales industry & \\
\hline 2 & Automobile sales industry & & 3 & Agro-industry & & 2 & Services & \\
\hline 2 & Electronic and electrical trade & & 3 & Trade & & 2 & Pharmaceutical products & \\
\hline 1 & Services & & 1 & Distribution of food products & & 1 & Chemicals and chemical products & \\
\hline 1 & Agro-industry & & 2 & Electrical and electronic material industry & & 3 & Telecommunications & \\
\hline 1 & Transportation and distribution & $4-5$ & 1 & Services & & 2 & Wood, cork, and furniture & \\
\hline 1 & Pharmaceutical products & & 2 & Non-metallic mineral products & & 2 & Electrical and electronic material industry & \\
\hline 2 & Trade & & 1 & Construction industry & & 2 & Textiles & \\
\hline 1 & Distribution of combustible & & 1 & Pharmaceutical products & & 1 & Hotels and restaurants & \\
\hline 1 & Automobile sales industry & & 1 & Distribution of combustible & & 1 & Transport equipment industry & \\
\hline 1 & Construction industry & & 1 & Chemicals and chemical products & & 1 & Non-metallic mineral products & \\
\hline 1 & Chemicals and chemical products & & 2 & Construction industry & 7 & 1 & Electronic and electrical trade & \\
\hline 2 & Distribution of combustible & 5 & 3 & Electrical and electronic material industry & & 1 & Distribution of combustible & \\
\hline 3 & Trade & & 3 & Services & & 1 & Electricity, gas and water supply & \\
\hline 1 & Publishing industry & & 4 & Pharmaceutical products & & 1 & Trade & $8-9$ \\
\hline 2 & Electronic and electrical trade & & 2 & Distribution of food products & & 2 & Agro-industry & \\
\hline 1 & Hygiene and cleaning & & 1 & Publishing industry & & 2 & Non-metallic mineral products & \\
\hline 1 & Electrical and electronic material industry & & 2 & Transport equipment industry & & 2 & Textiles & \\
\hline 1 & Chemicals and chemical products & & 3 & Automobile sales industry & & 10 & Construction industry & \\
\hline 1 & Cellulose and paper & & 3 & Non-metallic mineral products & & 2 & Publishing industry & \\
\hline 2 & Construction industry & & 2 & Trade & & 2 & Hotels and restaurants & \\
\hline 1 & Agro-industry & & 1 & Chemicals and chemical products & & 2 & Basic metals & \\
\hline 1 & Basic metals & $5-6$ & 1 & Distribution of combustible & & 1 & Electronic and electrical trade & \\
\hline 1 & Wood, cork, and furniture & & 1 & Transportation and distribution & & 1 & Services & \\
\hline 2 & Chemicals and chemical products & & 3 & Pharmaceutical products & $7-8$ & 4 & Automobile sales industry & \\
\hline 1 & Services & & 2 & Construction industry & & 2 & Clothes and leather & \\
\hline
\end{tabular}


1 Distribution of combustible

5 Pharmaceutical products

Line missing
Distribution of

combustible

Basic metals

3

1

Distribution of food

products

Distribution of food

products 
change? These are only two of the questions which frequently cannot be answered when weighted-sum methods are used. Such methods are counterproductive as the weights they find are meaningless. In outranking-based methodologies the weights represent the relative importance of criteria; as such no average is calculated. These methods are based on two major concepts: concordance and discordance (see Roy, 1996).

In this study, the SRF software built 12 different sets of weights $(3$ rankings $\times 2$ scenarios regarding the relative importance of the most important criterion versus the least important one $\times 2$ options for blank cards per ranking). See Table 5. ELECTRE III used these 12 different sets of weights in order to obtain the 12 rankings of the alternatives.

\section{Results}

After obtaining the rankings we derive some conclusions. Since it is difficult to deal with the 12 rankings of 392 firms, we used the one way ANOVA (ANalysis Of VAriance) to assess the mean of these 12 rankings and the Newman-Keuls rang test for the means at the 0.01 level of significance. This test analyses the difference between means and finds the ones significantly different from the others. We only are interested to look at the "good" firms and check for the management practices used by those firms. The Newman-Keuls test was used to "identify" the subset of firms with the "best" economical and financial performance. According to this test the position of a given subset of firms in the ranking is defined as follows. A subset of the firms includes all the firms whose the average position in the 12 rankings is not significantly different, and differ significantly from the average position of the firms included in any other subset. The shadow subsets, include the firms that the average position in the rankings considered do not differ significantly from neither the firms belonging to the subsets below and above the average position in the rankings.

Table 6 presents the positions of the firms' subsets according to their economical and financial performance, and economic sector. Based on these results, the following conclusion is reported. In the first subset two firms were identified (one belonging to in the trade sector and other in the pharmaceutical sector). This is consistent with a previous study were it was found that profitability of the Portuguese firms does not depend neither on size nor on sector (Lisboa and Augusto, 2003).
Based on the results of the multiple criteria procedure, field studies were conducted. These field studies attempted to shed some light on the practices of firms which made a kind of the "very good" ones. The investigations in these field studies focused on operational and strategic practices, characteristics and initiatives of these leading organizations. The results of the field studies for the two leading firms are summarized in Table 7. The field studies were conducted using a qualitative scale questionnaire. The leadings firms expressed their practices and characteristics in terms of three levels (high, medium and low). For the majority of the items in the questionnaire, the answers given by the firms were coincident. When the answers were not coincident the correspondent item was classified with the lowest answer.

These results clearly underscore the commitment of these organizations to the different facets of organizational excellence. It refers to firms which are well-recognized by the public as leaders in their industries. In this context, not only that these organizations exhibited the strong commitment to excellence, but they were also able to translate this apparent commitment into outstanding performance. As such, they were able to distinguish themselves from other organization. Based on the field studies results, it was evident that these organizations have succeeded in adapting an open system approach to their strategy, operations, and relations to suppliers and customers. This open system approach was facilitated and sustained by excellent management-employees relations and the willingness to benchmark best practices.

In short, these organizations can be described as systematic, customer-focused, employees-oriented, and as having strong relationships with their suppliers. In addition, these organizations appeared to respect the natural environment and the communities in which they conduct business.

\section{Concluding remarks}

In this research, a multiple criteria approach is used to rank the performance of Portuguese firms in different economic sectors. The ranking of these firms resulted in different classes of performance. The financial ratios used in this study as performance measures were used to rank the firms and not to generate references indicators for benchmarking. Once a collective financial performance was used to identify "best" firms, field studies were 
Table 7

Practices and characteristics of the leading firms: A summary of the field studies

\begin{tabular}{|c|c|c|c|}
\hline \multirow[t]{2}{*}{ Practices and characteristics } & \multicolumn{3}{|l|}{ Level } \\
\hline & High & Medium & Low \\
\hline Use of strategic planning & $X$ & & \\
\hline Use of strategic information systems & $\mathrm{X}$ & & \\
\hline Use of competitive analysis & $\mathrm{X}$ & & \\
\hline Have systematic e-business practices and strategy & $\mathrm{X}$ & & \\
\hline Top management involvement & $\mathrm{X}$ & & \\
\hline Use of forecasting models & $\mathrm{X}$ & & \\
\hline Use of JIT & & $\mathrm{X}$ & \\
\hline Use of automated production systems & $\mathrm{X}$ & & \\
\hline Use of benchmarking & $\mathrm{X}$ & & \\
\hline Use of TQM and CI & $\mathrm{X}$ & & \\
\hline Use of process re-engineering & & $\mathrm{X}$ & \\
\hline Use of information systems to promote efficiency and quality of the operation & $\mathrm{X}$ & & \\
\hline Use of production planing models & $\mathrm{X}$ & & \\
\hline Use of Root-cause analysis & $\mathrm{X}$ & & \\
\hline Use of reliable suppliers & $\mathrm{X}$ & & \\
\hline Use of electronic information exchange with suppliers & & $\mathrm{X}$ & \\
\hline Use of JIT with suppliers & & $\mathrm{X}$ & \\
\hline Use of customers focus groups and surveys & $\mathrm{X}$ & & \\
\hline Use of customers profiling & $\mathrm{X}$ & & \\
\hline Use of customers satisfaction tracking on a long-term basis & $\mathrm{X}$ & & \\
\hline Use of joint programs with customers to promote quality improvements & $\mathrm{X}$ & & \\
\hline Use of employees performance trucking systems & $\mathrm{X}$ & & \\
\hline Use of employees rewards systems & $\mathrm{X}$ & & \\
\hline Use of information system to promote communication with employees & $\mathrm{X}$ & & \\
\hline Use of profit-sharing plans for employees & & $\mathrm{X}$ & \\
\hline Use of systematic promotion and termination policies & $\mathrm{X}$ & & \\
\hline Maintain strong relationships with the community & $\mathrm{X}$ & & \\
\hline Adhere to laws and regulations related to the natural environment & & $\mathrm{X}$ & \\
\hline
\end{tabular}

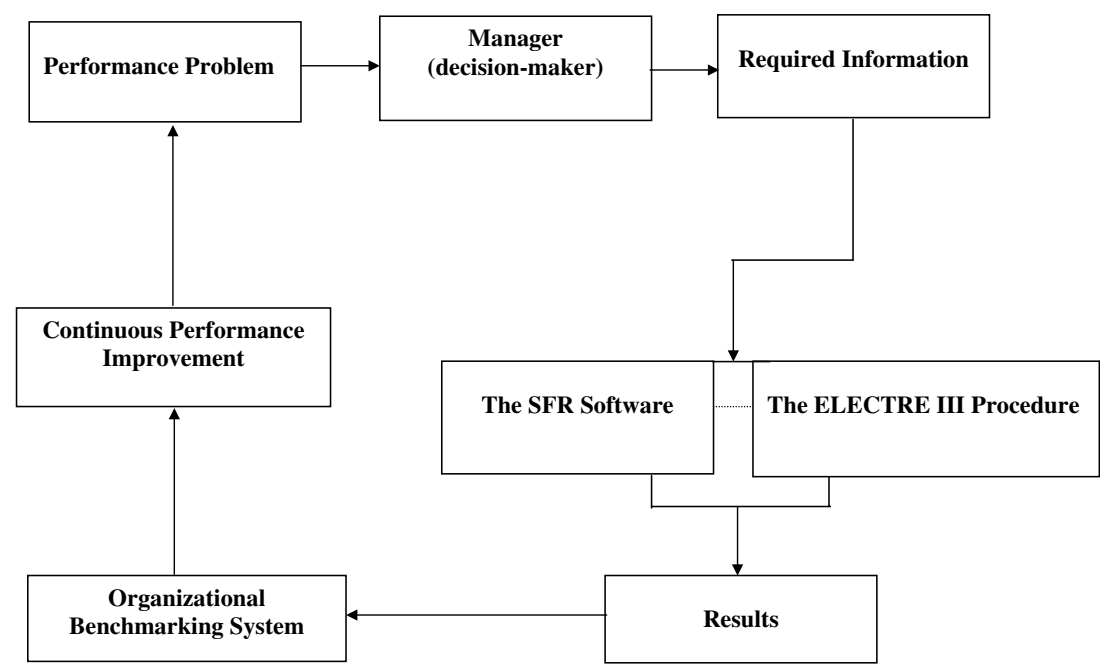

Fig. 1. A multiple criteria performance in a benchmarking context.

used to identify the practices carried out by these firms. These practices rather than the financial ratios (measures) were the subject of benchmarking. Therefore, these practices as opposed to the 
financial indicators are what this research is stressing in the context of benchmarking.

The profile of high performing firms can be used by other firms for benchmarking purposes. The conceptual framework in Fig. 1 is designed to facilitate the integration of the multiple criteria procedure results with the organizational benchmarking system. As such, the framework offers a conceptual linkage between a proven performance measurement methodology and the organizational benchmarking system. This linkage is critical to the benchmarking efforts of organizations, as they pursuit continuous performance improvements.

\section{References}

Ammar, S., Wright, R., Selden, S., 2000. Ranking state financial management: A multilevel fuzzy rule-based system. Decision Sciences 31 (2), 449-481.
Figueira, J., Roy, B., 2002. Determining the weights of criteria in the ELECTRE type methods with a revised Simos' procedure. European Journal of Operational Research 139, 317326.

Figueira, J., Greco, S., Ehrgott, M., 2005. Decision analysis: The state of the art surveys. Springer Science and Business Media, Inc., New York.

Kerr, D., 1999. Mergers shake up international company ranking. Oil and Gas Investor 19 (2), 18.

Lisboa, J., Augusto, M.G., 2003. Dimensão e Rendibilidade: O caso da Indústria Transformadora Portuguesa. Portuguese Journal of Management Studies 2 (8), 131-143.

Roy, B., 1996. Multicriteria methodology for decision aiding. Kluwer Academic Publishers, Dordrecht.

Roy, B., Bouyssou, D., 1993. Aide multicritère à la décision: Méthodes et cas. Economica, Collection Gestion, Paris.

Thurston, C.W., 2001. World's biggest banks 2001. Global Finance 15 (11), 80-81.

Wolin, M.L., 2001. Review 200: Members of the jury. Far Eastern Economic Review 163 (52), 92. 